\title{
The role of cadherin-11 in microcystin-LR-induced migration and invasion in colorectal carcinoma cells
}

\author{
QIANGQIANG ZHU ${ }^{1 *}$, ZHEN WANG $^{2 *}$, LIHUA ZHOU $^{3,4^{*}}$, YAN REN $^{1}$, \\ YING GONG ${ }^{5}$, WEI QIN ${ }^{6}$, LIN BAI $^{3}$, JUN HU $^{3}$ and TING WANG ${ }^{1}$ \\ ${ }^{1}$ Department of Cell Biology, Nanjing Medical University, Nanjing, Jiangsu 211166; ${ }^{2}$ Department of Pathology, \\ The First Affiliated Hospital with Nanjing Medical University, Nanjing, Jiangsu 210029; ${ }^{3}$ Clinical Medicine School, \\ Nanjing Medical University, Nanjing, Jiangsu 211166; ${ }^{4}$ Department of Neurology, The First Affiliated Hospital of \\ Soochow University, Suzhou, Jiangsu 215000; ${ }^{5}$ Department of Pharmacy, The Fourth People's Hospital of Jinan City, \\ Jinan, Shandong 250000; ${ }^{6}$ School of Pharmacy, Nanjing Medical University, Nanjing, Jiangsu 211166, P.R. China
}

Received April 4, 2016; Accepted June 5, 2017

DOI: $10.3892 / \mathrm{ol} .2017 .7458$

\begin{abstract}
The present study aimed to explore whether microcystin-LR (MC-LR; a well-known cyanobacterial toxin produced in eutrophic lakes or reservoirs) induced tumor progression by activating cadherin-11(CDH11). A previous tumor metastasis PCR array demonstrated that MC-LR exposure resulted in a significant increase in the expression of CDH11. In the present study, to confirm the effect of the MC-LR treatment on CDH11 expression, HT-29 cell migration and invasion following MC-LR treatment were tested by Transwell assays, and protein levels of CDH11 were tested by immunofluorescence and western blot analysis. The results demonstrated that MC-LR activated CDH11 expression in addition to cell migration and invasion in HT-29 cells. To further investigate the association between MC-LR-induced CDH11 upregulation, and higher motility and invasiveness in HT-29 cells, knockdown of CDH11 using small interfering RNA (siRNA) in HT-29 cells was performed. Subsequent Transwell assays confirmed that MC-LR-induced enhancement of migration and invasion was significantly decreased following CDH11 knockdown by CDH11-siRNA in HT-29 cells. The results from the present study indicate that MC-LR
\end{abstract}

Correspondence to: Dr Ting Wang, Department of Cell Biology, Nanjing Medical University, 140 Hanzhong Road, Nanjing, Jiangsu 211166, P.R. China

E-mail: wangting@njmu.edu.cn

*Contributed equally

Abbreviations: MC-LR, microcystin-LR; CDH11, cadherin-11; siRNA, small interfering RNA; amot, angiomotin; MMPs, matrix metalloproteinases; MAPKs, mitogen-activated protein kinases; $N F-\kappa B$, nuclear factor- $\kappa \mathrm{B} ; \mathrm{TNF}-\alpha$, tumor necrosis factor- $\alpha$

Key words: microcystin-LR, colorectal cancer, cadherin-11, migration, invasion may act as a CDH11 activator to promote HT-29 cell migration and invasion.

\section{Introduction}

Cyanobacteria frequently form water blooms in eutrophic lakes or reservoirs. Microcystins, as important secondary metabolites of cyanobacteria, include $>90$ known structural variants (1), and have been demonstrated to contribute to livestock poisoning and higher incidences of primary human carcinoma, including liver carcinoma (2), colorectal carcinoma (3) and oral cancer (4) via drinking water and food chains. Among the variants of microcystins, microcystin-LR (MC-LR) is the most poisonous and is a tumor initiator in humans $(5,6)$. Recently, efforts have been made to investigate the molecular mechanisms underlying MC-LR-induced carcinogenesis $(7,8)$. However, little is known about the association between MC-LR exposure and tumor migration and invasion, which is the primary cause of mortality or poor prognosis in patients with cancer (9).

Cadherins are from a superfamily of $>100$ transmembrane glycoproteins that mediate intercellular adhesion by calcium-dependent homophilic interactions (10). Cadherins serve important roles in cell-cell junctions, tissue architecture and cell polarity in addition to cell movement and proliferation (11). It has previously been demonstrated that that CDH1/E-cadherin (12) and CDH13/H-cadherin (13) are functional tumor suppressors, while little is known about whether other cadherins exhibit cancer-associated activity. Cadherin-11 (CDH11), also known as osteoblast cadherin, is broadly expressed in human normal mesoderm-derived tissues (14). Previous studies have reported that CDH11 is associated with tumorigenesis and tumor progression; its tumor-promoting activity was reported in prostate cancer (15), breast cancer (16) and glioblastoma (17).

Previous studies from our group revealed the active effect of MC-LR on cancer cell migration and invasion (18-20) and a previous tumor metastasis PCR array demonstrated that MC-LR exposure significantly increased the expression of eight genes, including CDH11 (20). In the present study, the 
data demonstrated that MC-LR enhances carcinoma cell motility and invasiveness by regulating CDH11 expression in human colorectal cancer HT-29 cells.

\section{Materials and methods}

Cell culture and exposure. HT-29 cells were obtained from the American Type Culture Collection (Manassas, VA, USA) and maintained in a monolayer culture in Dulbecco's modified Eagle's medium (DMEM; Hyclone; GE Healthcare Life Sciences, Logan, UT, USA), containing $100 \mu \mathrm{g} / \mathrm{ml}$ streptomycin, $100 \mu \mathrm{g} / \mathrm{ml}$ penicillin and $10 \%$ fetal bovine serum (FBS; Hyclone; GE Healthcare Life Sciences). Cells were cultured in a humidified atmosphere of $5 \% \mathrm{CO}_{2}$ at $37^{\circ} \mathrm{C}$. HT- 29 cell culture was performed according to the manufacturer's protocol and as previously described by Miao et al (18). MC-LR (Enzo Life Sciences, Inc., Farmingdale, NY, USA) was dissolved in sterile water to make a $0.25 \mathrm{nM}$ stock solution and then added in the medium to reach different doses $(0,1,5,12.5,25$ and $50 \mathrm{nM})$.

Cellular immunofluorescence. After $48 \mathrm{~h}$ treatment with MC-LR of $25 \mathrm{nM}$, cells grown on coverslips were washed with PBS, fixed by immersion at room temperature with $4 \%$ polyformaldehyde for $15 \mathrm{~min}$ and permeabilized with $0.1 \%$ Triton-X-100 in PBS at $4^{\circ} \mathrm{C}$ for 15 min. Slides were then washed with PBS and blocked with blocking buffer consisting of $4 \%$ bovine serum albumin (Sigma-Aldrich; Merck KGaA, Darmstadt, Germany) in PBS for 30 min at room temperature. The cells were then incubated with a mouse anti-human CDH11 monoclonal antibody (cat. no. MAB1790; $1 \mu \mathrm{g} / \mathrm{ml}$; R\&D Systems, Inc., Minneapolis, MN, USA) in blocking buffer overnight at $4^{\circ} \mathrm{C}$, followed by incubation with a goat anti-mouse phycoerythrin-labeled antibody (cat. no. sc-3738; dilution, 1:100; Santa Cruz Biotechnology, Inc., Dallas, TX, USA) in blocking buffer at room temperature for $2 \mathrm{~h}$. Then cells on coverslips were captured and analyzed by fluorescence microscopy (magnification, x400; Axio Observer A1; Carl Zeiss AG, Oberkochen, Germany). Cellular immunofluorescence was performed according to the manufacturer's protocol and as previously described by Zhang et al (20).

Knockdown of CDH11 using small interfering RNA in HT-29 cells. The CDH11 and negative control small interfering RNAs (siRNAs) were purchased from Invitrogen (Thermo Fisher Scientific, Inc., Waltham, MA, USA). The sequences of each siRNA were as follows: CDH11 number 1, 5'-AGG AAGUAGGAAGAGUGAAAGCUAA-3'; CDH11 number 2, 5'-CAACAUCACUGUCUU UGCAGCAGA A-3'; and CDH11 number 3, 5'-CAUCGUCAUUCUCCUGGUCAU UGUA-3' (21), these three siRNA sequences were mixed at a ratio of 1:1:1 prior to the experiment. A random sequence control was used as the negative control (forward, 5'-UUC UCCGAACGUGUCACGUTT-3' and reverse, 5'-ACG UGACACGUUCGGAGAATT-3'). Cells were plated at a density of $8 \times 10^{4}$ cells/well in six-well plates. Following pre-incubation of the siRNA with Lipofectamine ${ }^{\circledR} 2000$ (Invitrogen; Thermo Fisher Scientific, Inc.) in serum-free Opti-MEM medium (Invitrogen; Thermo Fisher Scientific, Inc.) for $20 \mathrm{~min}$, cells were transfected with $\mathrm{CDH} 11$ or negative control siRNA oligo duplexes for $6 \mathrm{~h}$, then cells were switched into fresh medium and incubated at $37^{\circ} \mathrm{C}$ in a humidified atmosphere of $5 \% \mathrm{CO}_{2}$. Following $24 \mathrm{~h}$, cells were collected and used for migration or invasion assays, and $48 \mathrm{~h}$ later for western blot analysis. All transfections were performed according to the manufacturer's protocol and as previously described (18).

Western blotting. To investigate CDH11 expression, a standard western blotting analysis was conducted. Following $48 \mathrm{~h}$ culture with MC-LR, or being transfected with CDH11 or negative control siRNA oligoduplexes, the cells were lysed with RIPA cell lysis buffer 1 (Beyotime Institute of Biotechnology, Haimen, China) containing $1 \mathrm{mM}$ phenylmethylsulfonyl fluoride. The total cellular protein (30 $\mu \mathrm{g} / \mathrm{lane})$ was then boiled for $5 \mathrm{~min}$ in SDS-sample buffer (Beyotime Institute of Biotechnology) before being subjected to SDS-PAGE (8\%) and transferred onto polyvinylidene difluoride membranes (EMD Millipore, Billerica, MA, USA). Membranes were then blocked for $2 \mathrm{~h}$ with nonfat dry milk in sterile water at room temperature and then incubated overnight at $4^{\circ} \mathrm{C}$ with a mouse anti-human $\mathrm{CDH} 11$ monoclonal antibody (cat. no. 32-1700; $2 \mu \mathrm{g} / \mathrm{ml}$; Invitrogen; Thermo Fisher Scientific, Inc.). Following four washes in TBS-Tween, membranes were incubated with a horse anti-mouse secondary antibody (cat. no. 7076; dilution, 1:1,000; Cell Signaling Technology, Inc., Danvers, MA, USA) for $2 \mathrm{~h}$. The blots were visualized by Enhanced Chemiluminescence (Thermo Fisher Scientific, Inc.) and imaged using aTanon-5200 imaging system machine (Tanon Science and Technology, Co., Ltd., Nanjing, China) and the membrane was probed with an anti-GAPDH antibody (cat. no. 5174; dilution 1:2,000; Cell Signaling Technology, Inc.) to confirm equal loading. The specific western blot assay method was performed according to the manufacturer's protocol and as described by Miao et al (18), andthe quantitative analysis was performed usingGel Image System version 4.00 (Tanon Science and Technology, Co., Ltd., Shanghai, China).

Migration and invasion assay. Transwell assays were conducted to investigate the motility and invasiveness of HT-29 cells. Cell migration assays were performed in 24-well Transwell chambers with $8.0-\mu \mathrm{m}$ pore size transwell inserts (Costar; Corning Incorporated, Corning, NY, USA,). Cell invasion assays were investigated using an 8.0- $\mu \mathrm{m}$ filter coated with $30 \mu \mathrm{l}$ of $0.5 \%$ Matrigel (Sigma-Aldrich; Merck KGaA). Transwell assays were performed according to the manufacturer's protocol and as previous described (18). Briefly, $4 \times 10^{4}$ cells treated with MC-LR or transfected with siRNA were added to the upper chamber of DMEM, and DMEM with $10 \%$ FBS was added to the lower chamber. Following incubation for 48 or $72 \mathrm{~h}$ (migration assay) and 72 or $96 \mathrm{~h}$ (invasion assay) at $37^{\circ} \mathrm{C}$ in a humidified atmosphere of $5 \% \mathrm{CO}_{2}$, cells on the upper surface were removed completely by gentle wiping with a cotton swab. Cells that penetrated through pores and adhered to the underside of the filters were then fixed with $4 \%$ paraformaldehyde and stained with $0.02 \%$ crystal violet solution containing $20 \%$ ethanol. Then cells were observed and counted under light microscopy (magnification, x100) (CKX41 microscope; Olympus Corporation, Tokyo, Japan). For each 
A

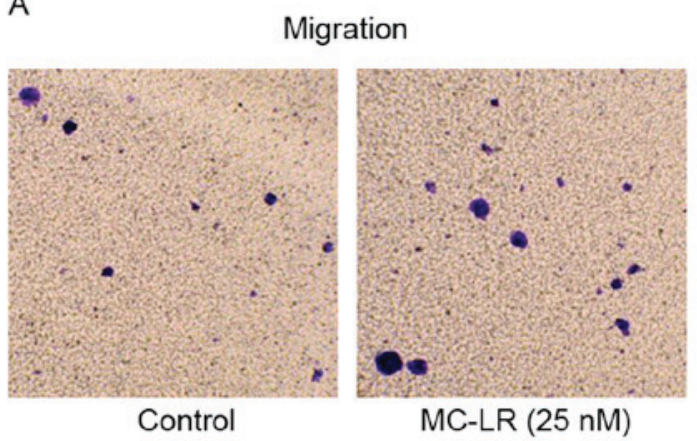

B

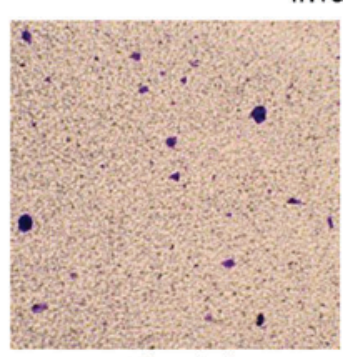

Control
Invasion

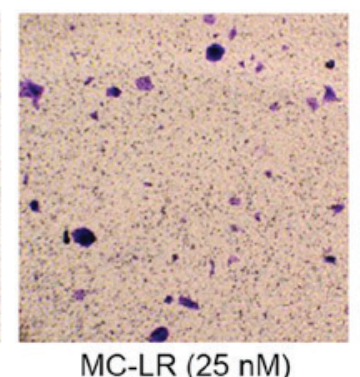

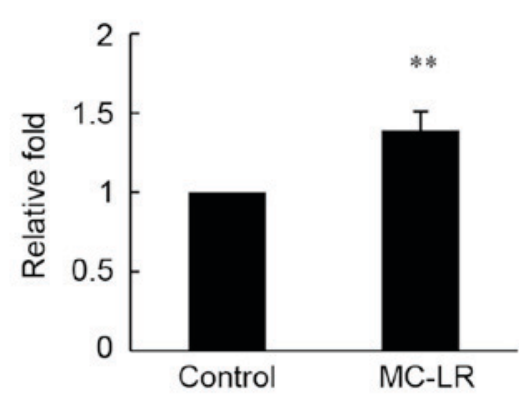

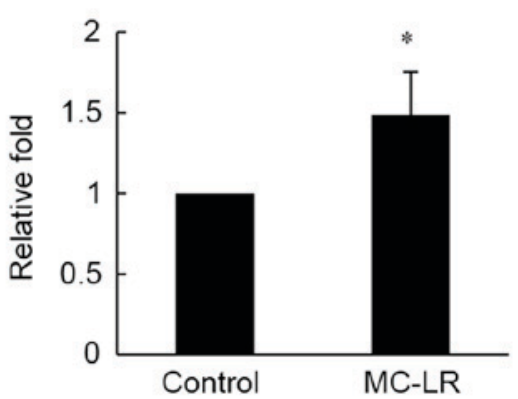

Figure 1. MC-LR induces the migration and invasion of HT-29 cells. Cell motility and invasiveness were examined by (A) cell migration assays (48 h) and (B) cell invasion assays (72 h). Magnification, x100. Bars represent mean \pm standard deviation of numbers of translocated cells from three independent experiments. ${ }^{*} \mathrm{P}<0.05$ and ${ }^{* *} \mathrm{P}<0.01$ vs. the control (without MC-LR treatment). MC-LR, microcystin-LR.

replicate $(n=3)$, cells in three randomly selected fields per well were counted and averaged. Data are expressed as a ratio to the control (no MC-LR treatment but negative control siRNA treatment). Tumor cell motility and invasiveness was defined as the mean number of the treated cells.

Statistical analysis. All statistical analyses were carried out by two-tailed Student's t-test or a one-way analysis of variance. Data are presented as the mean \pm standard deviation from three different experiments. $\mathrm{P}<0.05$ was considered to indicate a statistically significant difference. Computer-based calculations were conducted using Microsoft Excel 2007 (Microsoft Corporation, Redmond, WA, USA).

\section{Results}

Activation of cell migration and invasion in microcystin-LR-treated HT-29 cells. To investigate the motility and invasiveness of the HT-29 cells following MC-LR treatment, Transwell chamber assays were performed. In the present study, MC-LR at $25 \mathrm{nM}$ promoted migration and invasion of HT-29 cells and significantly increased the number of translocated cells compared with the control group (Fig. 1). MC-LR treatment resulted in a 1.4 -fold increase in cell migration $(\mathrm{P}<0.01$; Fig. 1A), suggesting that MC-LR induces migration of HT-29 cells. The results from the invasion assay in HT-29 cells demonstrated that MC-LR exposure led to a 1.5 -fold increase in cell number compared with the control group $(\mathrm{P}<0.05$; Fig. 1B).

Upregulation of CDH11 in microcystin-LR-treated HT-29 cells. To confirm the effect of MC-LR treatment on CDH11 expression, the protein levels of CDH11 in HT-29cancer cells treated with different concentrations of MC-LR were investigated. MC-LR treatment resulted in a significant increase in CDH11 expression in HT-29cancer cells as measured by cellular immune fluorescence. Compared with the control, cell treatment with $25 \mathrm{nM}$ of MC-LR produced a 1.9-fold raise in fluorescence intensity of CDH11 ( $\mathrm{P}<0.01$; Fig. 2A). Similar to the results of immunofluorescence assays, western blot analysis demonstrated a marked increase in protein levels with MC-LR treatment, particularly at 12.5, 25, $50 \mathrm{nM}$ compared with GAPDH expression (Fig. 2B). The results from cellular immunofluorescence and western blotting revealed that the protein level of CDH11 is upregulated by MC-LR in HT-29 cells, which may mediate the effects of MC-LR on cell migration and invasion.

Inhibition of migration and invasion following knockdown of CDH11 in HT-29cells. Tofurtherevaluate the association between MC-LR-induced CDH11 overexpression, and tumor migration and invasion, an RNA interference assay was performed. Western blot analysis demonstrated that CDH11-siRNA markedly reduced the expression of CDH11 in HT-29 cells (Fig. 3A). Following treatment with CDH11-siRNA, cells exposed to MC-LR (25 nM; Group C) exhibited significantly decreased motility $(0.52$-fold; $\mathrm{P}<0.05)$ and invasiveness $(0.42$-fold; $\mathrm{P}<0.01)$ compared with the control group (Group A, negative control siRNA), whereas treatment with MC-LR in the presence of the negative control siRNA (Group B) significantly increased cell migration (0.43-fold; $\mathrm{P}<0.05)$ and invasion ( 0.73 -fold; $\mathrm{P}<0.01)$ compared with the control group (Group A), and in the presence of MC-LR, the knockdown of $\mathrm{CDH} 11$ reduced cell migration and invasion ability by approximately0.67-fold (Fig. 3B and C). 
A

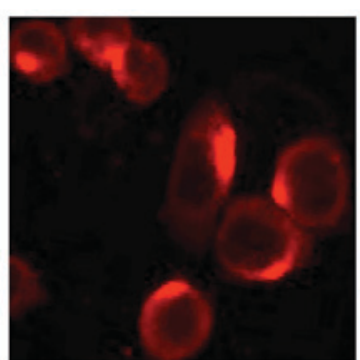

Control

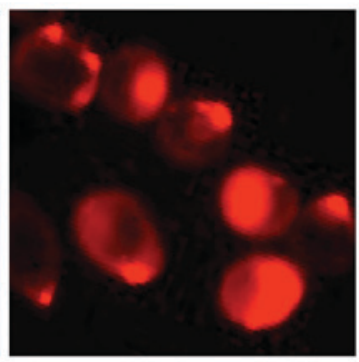

MC-LR (25 nM)

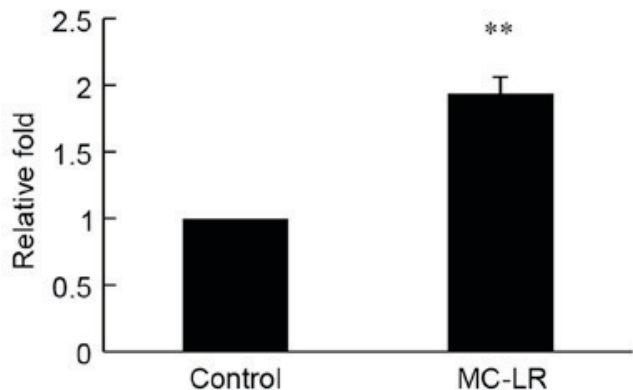

B

\section{$\mathrm{CDH} 11$ \\ GAPDH}

MC-LR (nM)

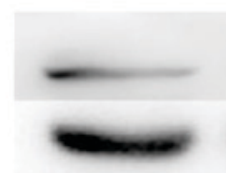

0

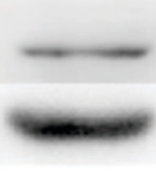

1

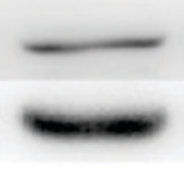

5

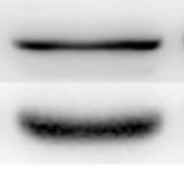

12.5

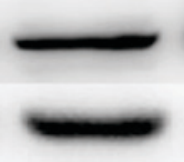

25

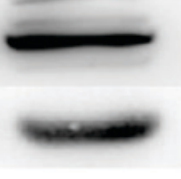

50

Figure 2. MC-LR induces the expression of CDH11 in HT-29 cells. Expression of CDH11 in HT-29 cells was detected by (A) cellular immunofluorescence and (B) western blotting analysis of CDH11 following treatment by MC-LR at different doses $(0,1,5,12.5,25$ and $50 \mathrm{nM})$ with GAPDH expression acting as the loading control. The fluorescence intensity of $\mathrm{CDH} 11$ of each immunofluorescence sample was calculated and analyzed. Magnification, x400. Bars represent mean \pm standard deviation of fluorescence intensity from three independent experiments. ${ }^{* *} \mathrm{P}<0.01$ vs. the negative control. MC-LR, microcystin-LR; CDH11, cadherin-11.

A

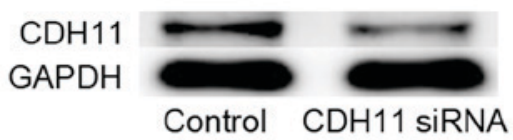

\section{B}

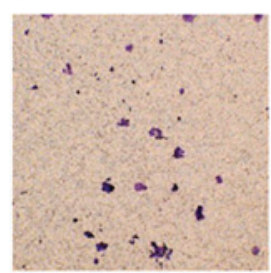

Group A

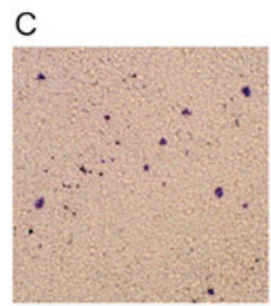

Group A
Migration

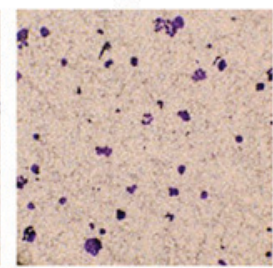

Group B

Invasion

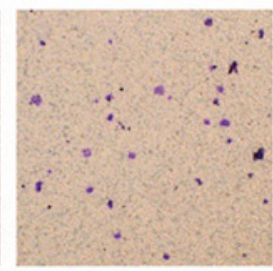

Group B

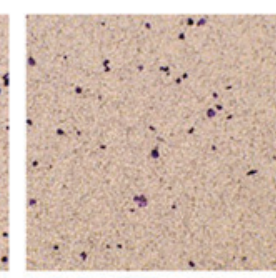

Group C

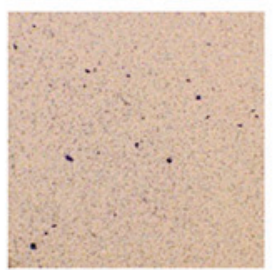

Group C
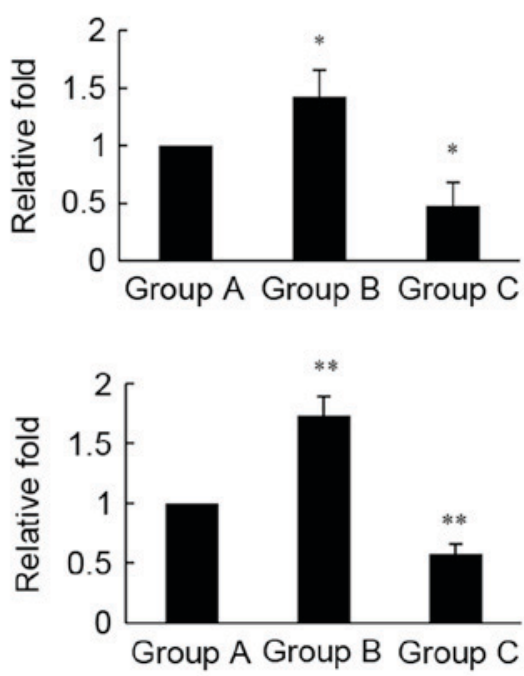

Figure 3. MC-LR-induced migration and invasion is antagonized by CDH11-siRNA in HT-29 cells. (A) HT-29 cells were transfected with CDH11 or negative control siRNA for $48 \mathrm{~h}$, and CDH11 protein levels were evaluated using western blotting analysis. GAPDH was probed as an internal control. (B) Cell migration assay (72 h) and (C) cell invasion assay (96 h) was performed to assess the motility and invasiveness of HT-29 cells following treatment with: Group A, negative control siRNA; Group B, negative control siRNA and MC-LR (25 nM); and Group C, CDH11 siRNA and MC-LR (25 nM). Magnification, x400. Bars represent mean \pm standard deviation of numbers of translocated cells from three independent experiments. " $\mathrm{P}<0.05$ and ${ }^{* * *} \mathrm{P}<0.01$ vs. Group $\mathrm{A}$. MC-LR, microcystin-LR; CDH11, cadherin-11; siRNA, small interfering RNA.

These data revealed that MC-LR-induced migration and invasion decreases following CDH11 knockdown, suggesting that CDH11 serves an important role in MC-LR-induced migration and invasion of HT-29 cells.

\section{Discussion}

Colorectal carcinoma is one of the most frequent forms of cancer in humans and is among the leading causes of 
cancer-associated mortality, which is primarily caused by cancer cell metastasis (9). Previous studies have demonstrated that MC-LR serves a role as a tumor initiator $(2-4,6)$; however, the molecular mechanisms underlying this effect remain unclear. A previous study by our group demonstrated that MC-LR promotes migration and invasion of a number of colorectal cell lines, including HT-29 cells (18). A previous tumor metastasis PCR array demonstrated that the expression of CDH11geneincreased significantly following MC-LR exposure (20). The results from the present study suggested that MC-LR upregulates CDH11, and enhances migration and invasion, as migration and invasion induced by MC-LR was suppressed by silencing of CDH11 in HT-29 cells. These results suggest that $\mathrm{CDH} 11$ is a tumor promoter that serves an important role in MC-LR-induced migration and invasion.

A previous study reported MC-LR induces reorganization or collapse of the cytoskeleton (22), which may be responsible for increased migration and invasion induced by MC-LR. CDH11 contains a cytoplasmic tail that binds to p120 catenin and $\beta$-catenin like other cadherin family members (23). p120 catenin mediates small GTPases, including Rho and Rac (24), and attaches cadherin to microtubules (25), while $\beta$-catenin interacts with $\alpha$-catenin, which regulates the actin cytoskeleton (24). In addition, Li et al (26) has also reported that CDH11 recruits Rac-specific GEFTrio to the plasma membrane, which elevates Rac activity and promotes the formation of membrane ruffles (27) in breast tumorigenesis $(26,28)$. Therefore, CDH11 may serve a role in cytoskeleton reorganization and cell motility induced by MC-LR. Another study demonstrated that human angiomotin (Amot)-p80 is a distinct component of the CDH11 protein complex and deletion of the Amot binding motif in the CDH11 cytoplasmic domain significantly reduces migration of human prostate cancer cells (29), which is in line with the results of the present study, which demonstrated that knockdown of CDH11 leads to inhibition of cell migration. In addition, it was reported that CDH11 engagement increases the expression of matrix metalloproteinases (MMPs) through a mitogen-activated protein kinase (MAPK) and nuclear factor- $\kappa \mathrm{B}(\mathrm{NF}-\kappa \mathrm{B})$-dependent signaling pathway in rheumatoid arthritis synovial fibroblasts (30). MMP overexpression promotes cell invasion through degradation of the basement membrane (31); this may be responsible for the reduction of cell invasion and inhibition following CDH11 knockdown. A previous study reported that MC-LR exposure increases MMP-2/-9 expression and promotes melanoma cell invasion by activating phosphatidylinositol 3-kinase/RAC-alpha serine/threonine-protein kinase (19) and $\mathrm{NF}-\kappa \mathrm{B}$ signaling (20). MMPs may serve an important role in MC-LR and CDH11-induced cell invasion. MC-LR may upregulate CDH11 through a MC-LR-NF- $\kappa \mathrm{B}$ signaling axis, which requires further study. In addition, it has been reported that tumor necrosis factor- $\alpha$ (TNF- $\alpha$ ) induces CDH11 expression in vascular smooth muscle cell and inhibition of CDH11 attenuates smooth muscle cell migration (32). TNF- $\alpha$ is a inflammation and tumor promoter (33) that may be induced by activation of the NF- $\kappa \mathrm{B}$ signaling pathway (34). A previous study revealed that MC-LR induced TNF- $\alpha$ expression in the cells of target tissues and that TNF- $\alpha$ is an endogenous tumor promoter (35). Therefore, TNF- $\alpha$ may serve a role in MC-LR-induced CDH11 upregulation.
The present study suggests that silencing of CDH11 expression may be a potential novel and promising therapeutic strategy for treating and improving the survival rate of patients with colorectal cancer induced by MC-LR or other CDH11-dependent malignancies. Future work may include prolonged exposure of sublethal concentrations of MC-LR in nude mice models, and the elucidation of possible molecular mechanisms mediating MC-LR-induced CDH11 activation and CDH11-promoted migration and invasion.

\section{Acknowledgements}

The present study was financially supported by the National Natural Science Foundation of China (grant nos. 21177062 and 21577066), the Priority Academic Program Development of Jiangsu Higher Education Institutions (grant no. JX10131801049) and the Innovation and Entrepreneurship Training Program for College Students in Jiangsu Province (grant no. 201410312044Y).

\section{References}

1. Chakrabarti SK, Bai C and Subramanian KS: DNA-Protein crosslinks induced by nickel compounds in isolated rat renal cortical cells and its antagonism by specific amino acids and magnesium ion. Toxicol Appl Pharmacol 154: 245-255, 1999.

2. Ueno Y, Nagata S, Tsutsumi T, Hasegawa A, Watanabe MF Park HD, Chen GC, Chen G and Yu SZ: Detection of microcystins, a blue-green algal hepatotoxin, in drinking water sampled in Haimen and Fusui, endemic areas of primary liver cancer in China, by highly sensitive immunoassay. Carcinogenesis 17 : 1317-1321, 1996.

3. Zhou L, Yu H and Chen K: Relationship between microcystin in drinking water and colorectal cancer. Biomed Environ Sci 15: 166-171, 2002.

4. Choi P, Jordan CD, Mendez E, Houck J, Yueh B, Farwell DG, Futran $\mathrm{N}$ and Chen $\mathrm{C}$ : Examination of oral cancer biomarkers by tissue microarray analysis. Arch Otolaryngol Head Neck Surg 134: 539-546, 2008.

5. Zhang H, Cai C, Fang W, Wang J, Zhang Y, Liu J and Jia X: Oxidative damage and apoptosis induced by microcystin-LR in the liver of Rana nigromaculata in vivo. Aquat Toxicol 140-141: 11-18, 2013.

6. Zegura B, Volcic M, Lah TT and Filipic M: Different sensitivities of human colon adenocarcinoma (CaCo-2), astrocytoma (IPDDC-A2) and lymphoblastoid (NCNC) cell lines to microcystin-LR induced reactive oxygen species and DNA damage. Toxicon 52: 518-525, 2008.

7. Gaudin J, Huet S, Jarry G and Fessard V: In vivo DNA damage induced by the cyanotoxin microcystin-LR: Comparison of intra-peritoneal and oral administrations by use of the comet assay. Mutat Res 652: 65-71, 2008.

8. Puerto M, Pichardo S, Jos A, Prieto AI, Sevilla E, Frías JE and Cameán AM: Differential oxidative stress responses to pure Microcystin-LR and Microcystin-containing and non-containing cyanobacterial crude extracts on Caco-2 cells. Toxicon 55: 514-522, 2010.

9. Yoon SS and Tanabe KK: Surgical treatment and other regional treatments for colorectal cancer liver metastases. Oncologist 4: 197-208, 1999.

10. Wheelock MJ and Johnson KR: Cadherins as modulators of cellular phenotype. Annu Rev Cell Dev Biol 19: 207-235, 2003.

11. Berx G and van Roy F: Involvement of members of the cadherin superfamily in cancer. Cold Spring Harb Perspect Biol 1: a003129, 2009.

12. Margulis A, Zhang W, Alt-Holland A, Crawford HC, Fusenig NE and Garlick JA: E-cadherin suppression accelerates squamous cell carcinoma progression in three-dimensional, human tissue constructs. Cancer Res 65: 1783-1791, 2005.

13. Andreeva AV and Kutuzov MA: Cadherin 13 in cancer. Gene Chromosome Cancer 49: 775-790, 2010.

14. Van Roy F: Beyond E-cadherin: Roles of other cadherin superfamily members in cancer. Nat Rev Cancer 14: 121-134, 2014 
15. Huang CF, Lira C, Chu K, Bilen MA, Lee YC, Ye X, Kim SM, Ortiz A, Wu FL, Logothetis CJ, et al: Cadherin-11 increases migration and invasion of prostate cancer cells and enhances their interaction with osteoblasts. Cancer Res 70: 4580-4589, 2010.

16. Pishvaian MJ, Feltes CM, Thompson P, Bussemakers MJ, Schalken JA and Byers SW: Cadherin-11 is expressed in invasive breast cancer cell lines. Cancer Res 59: 947-952, 1999.

17. Kaur H, Phillips-Mason PJ, Burden-Gulley SM, Kerstetter-Fogle AE,Basilion JP, Sloan AEand Brady-Kalnay SM: Cadherin-11, a marker of the mesenchymal phenotype, regulates glioblastoma cell migration and survival in vivo. Mol Cancer Res 10: 293-304, 2012.

18. Miao C, Ren Y, Chen M, Wang Z and Wang T: Microcystin-LR promotes migration and invasion of colorectal cancer through matrix metalloproteinase-13 up-regulation. Mol Carcinog 55: 514-524, 2015

19. Xu PF, Zhang XX, Miao C, Fu Z, Li Z, Zhang G, Zheng M, Liu Y, Yang $\mathrm{L}$ and Wang T: Promotion of melanoma cell invasion and tumor metastasis by microcystin-LR via phosphatidylinositol 3-Kinase/AKT pathway. Environ Sci Technol 47: 8801-8808, 2013

20. Zhang XX, Fu Z, Zhang Z, Miao C, Xu P, Wang T, Yang L and Cheng S: Microcystin-LR promotes melanoma cell invasion and enhances matrix metalloproteinase-2/-9 expression mediated by NF-kappaB activation. Environ Sci Technol 46: 11319-11326, 2012.

21. Yao H, Miura Y, Yoshioka S, Miura M, Hayashi Y, Tamura A, Iwasa M, Sato A, Hishita T, Higashi Y, et al: Parathyroid hormone enhances hematopoietic expansion via upregulation of cadherin-11 in bone marrow mesenchymal stromal cells. Stem Cells 32: 2245-2255, 2014.

22. Sun Y, Liu JH, Huang P, Guo ZL and Xu LH: Alterations of tau and VASP during microcystin-LR-induced cytoskeletal reorganization in a human liver cell line. Environ Toxicol 30: 92-100, 2015.

23. Brasch J, Harrison OJ, Honig B and Shapiro L: Thinking outside the cell: How cadherins drive adhesion. Trends Cell Biol 22: 299-310, 2012.

24. Cavallaro U and Dejana E: Adhesion molecule signalling: Not always a sticky business. Nat Rev Mol Cell Biol 12: 189-197, 2011.

25. Harris TJ and Tepass U: Adherens junctions: From molecules to morphogenesis. Nat Rev Mol Cell Biol 11: 502-514, 2010.
26. Li Y, Guo Z, Chen H, Dong Z, Pan ZK, Ding H, Su SB and Huang S: HOXC8-dependent cadherin 11 expression facilitates breast cancer cell migration through Trio and Rac. Genes Cancer 2: 880-888, 2011.

27. Ridley AJ: Rho GTPases and cell migration. J Cell Sci 114: 2713-2722, 2001

28. Li Y, Chao F, Huang B, Liu D, Kim J and Huang S: HOXC8 promotes breast tumorigenesis by transcriptionally facilitating cadherin-11 expression. Oncotarget 5: 2596-2607, 2014.

29. Ortiz A, Lee YC, Yu G, Liu HC, Lin SC, Bilen MA, Cho H, $\mathrm{Yu}-$ Lee LY and Lin SH: Angiomotin is a novel component of cadherin- $11 / \beta$-catenin/p120 complex and is critical for cadherin-11-mediated cell migration. FASEB J 29: 1080-1091, 2015.

30. Noss EH, Chang SK, Watts GF and Brenner MB: Modulation of matrix metalloproteinase production by rheumatoid arthritis synovial fibroblasts after cadherin 11 engagement. Arthritis Rheum 63: 3768-3778, 2011.

31. Roeb E, Arndt M, Jansen B, Schumpelick V and Matern S: Simultaneous determination of matrix metalloproteinase (MMP)-7, MMP-1, -3, and -13 gene expression by multiplex PCR in colorectal carcinomas. Int J Colorectal Dis 19: 518-524, 2004.

32. Monahan TS, Andersen ND, Panossian H, Kalish JA, Daniel S, Shrikhande GV, Ferran C and Logerfo FW: A novel function for cadherin 11/osteoblast-cadherin in vascular smooth muscle cells: Modulation of cell migration and proliferation. J Vasc Surg 45: 581-589, 2007.

33. Locksley RM, Killeen $\mathrm{N}$ and Lenardo MJ: The TNF and TNF receptor superfamilies: Integrating mammalian biology. Cell 104: 487-501, 2001.

34. Akira S, Uematsu S and Takeuchi O: Pathogen recognition and innate immunity. Cell 124: 783-801, 2006.

35. Fujiki $H$ and Suganuma M: Tumor promoters-microcystin-LR, nodularin and TNF-alpha and human cancer development. Anticancer Agents Med Chem 11: 4-18, 2011.

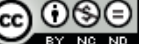

$$
\begin{aligned}
& \text { This work is licensed under a Creative Commons } \\
& \text { Attribution-NonCommercial-NoDerivatives } 4.0 \\
& \text { International (CC BY-NC-ND 4.0) License. }
\end{aligned}
$$

